\title{
A sequential explanatory mixed methods study design: An example of how to integrate data in a midwifery research project
}

\author{
Shwikar M.E. Othman*1,2, Mary Steen ${ }^{2}$, Julie-Anne Fleet ${ }^{2}$ \\ ${ }^{1}$ Obstetrics and Gynaecology Nursing Department, Faculty of Nursing, South Valley University, Egypt \\ ${ }^{2}$ UniSA Clinical and Health Sciences, University of South Australia, Australia
}

Received: August 10, 2020

DOI: $10.5430 /$ jnep.v11n2p75

\author{
Accepted: October 15, 2020 \\ Online Published: October 27, 2020 \\ URL: https://doi.org/10.5430/jnep.v11n2p75
}

\begin{abstract}
Integration of mixed methods involves bringing together quantitative and qualitative approaches and methodologies. Limited application in midwifery research has identified a need for practical examples. How to integrate two research approaches and methodologies in a sequential explanatory mixed methods study, at the design, methods, interpretation and reporting levels will be explained. This paper describes and discusses an example of how integration was used to develop a better understanding of midwives' knowledge and confidence after attending a healthy eating education workshop/webinar. This example illustrates how integration can be achieved and emphasises how a weaving technique can be used, and findings are presented in a joint display and extreme case analysis. The sequential explanatory design was adopted to merge and mix different datasets to be collected and analysed. Then, using meta-analysis to identify areas of convergence or discordance, which provided a more comprehensive overview and understanding of the key themes that linked midwives' knowledge and confidence. The application of this mixed methods design assisted in investigating and exploring midwives' knowledge and confidence levels and provided clear insights for midwives needs and the effectiveness of healthy eating education on practice.
\end{abstract}

Key Words: Sequential explanatory mixed methods, Integration, Education program, Healthy eating, Midwives

\section{INTRODUCTION}

\subsection{Why adopting a mixed methods study?}

A mixed methods study uses a paradigm which is a set of beliefs that guide a person's actions and reflects researcher's worldviews. ${ }^{[1]}$ Teddlie and Tashakkori ${ }^{[2]}$ define paradigm as 'a worldview, together with various philosophical assumptions associated with that point of view'. Worldview is the most common stance adopted for elements or dimensions of contrast, including four sets of philosophical beliefs. ${ }^{[2-4]}$ These four sets of philosophical beliefs are axiology (nature of human nature/ethics), epistemology (philosophical study of knowledge/nature of knowledge), ontology (nature of reality), and methodology (inquiry decisions). ${ }^{[1]}$ This worldview paradigm underpins the study design, approaches and methodologies adopted to conduct mixed methods research.

The mixed methods study design combines the strengths of both quantitative and qualitative approaches to answer research questions. This design includes quantitative and qualitative phases, and each phase is undertaken independently, followed by combining quantitative results and qualitative

\footnotetext{
* Correspondence: Shwikar M.E. Othman; Email: Shwikar.othman@mymail.unisa.edu.au; Address: UniSA Clinical and Health Sciences, University of South Australia, Australia.
} 
findings for a broader purpose and in-depth understanding of the research questions and phenomena. ${ }^{[5]}$ Data from both quantitative and qualitative phases are integrated into one mixed methods research design. ${ }^{[6]}$ A sequential explanatory mixed methods design was adopted to undertake a midwifery study as it was the best fit to answer the proposed research questions and draw on broader conclusions of findings. This midwifery study, a sequential explanatory design, commenced with a quantitative phase and was followed by a qualitative phase ${ }^{[7]}$ Both quantitative and qualitative data were collected, analysed separately during the research process then integrated. Triangulation was used to integrate the two phases, and this enabled interpretation of the combined findings. Findings from the qualitative phase were used to explain and provide a more comprehensive contextualisation of findings and interpretations drawn from quantitative phase. ${ }^{[8]}$

\subsection{Background to the midwifery study "investigated and explored midwives' levels of knowledge and con- fidence to provide healthy eating education for preg- nant women."}

Healthy eating during pregnancy has been well-recognised for its impact on maternal and fetal outcomes. ${ }^{[9]}$ The nutritional status of pregnant women is an essential factor in the healthy development of a baby, involving factors such as maternal dietary intake, body composition, blood flow to the uterus and placenta, and fetal genes. ${ }^{[9]}$ Midwives are in a unique position to promote better health and provide healthy eating education for pregnant women and their family members.

Midwives who have sufficient dietary knowledge and counselling skills have been shown to have a significant role in educating and influencing pregnant women to adopt healthy eating lifestyles. ${ }^{[10]}$ Furthermore, midwives have a positive attitude to providing healthy eating education to pregnant women. ${ }^{[11]}$ However, some midwives have an inadequate level of evidence-based nutritional knowledge and confidence to provide nutritional advice according to women's dietary and cultural backgrounds. ${ }^{[10,12]}$ Studies recommend further exploration of midwives' needs in terms of providing healthy eating education. ${ }^{[10,12]}$

A systematic review ${ }^{[13]}$ emphasised the essential role midwives have in providing healthy eating education to pregnant women. This review confirmed the need to provide continual and on-going healthy eating education for midwives and assess their knowledge and confidence levels in longitudinal studies. To address this research deficit, the current study incorporated a mixed methods approach to develop and evaluate a healthy eating education workshop/webinar. Midwives' level of knowledge and confidence was investigated prior to, immediately following, and 6-8 weeks after attending a workshop/webinar. ${ }^{[14]}$ Based on the systematic review findings, the following research questions were developed:

(1) What do South Australian midwives know and understand about healthy eating during pregnancy?

(2) How confident are midwives in providing information about healthy eating in pregnancy?

(3) What is the effectiveness of providing healthy eating education during pregnancy for midwives?

(4) What are the midwives' views and experiences of providing healthy eating advice to pregnant women after receiving the education?

\section{RESEARCH METHODOLOGY}

\subsection{The conceptual framework}

The philosophical assumptions and mixed methods methodology were used to construct the conceptual framework of this midwifery study. A conceptual framework is developed to provide justification for the significance of a research problem. This framework is also the researcher's explanation of how the research problem will be explored and explains the relationship between identified concepts and variables. ${ }^{[15]}$ Additionally, this framework describes a researcher's construct for the research process and is not based on other findings, theoretical or empirical publications. ${ }^{[16]}$ A conceptual framework provides a clear justification of the significance of the problem, using appropriate methods of data collection, analysis and interpretation, ${ }^{[16]}$ and can be presented in different ways such as concept maps, integrative diagrams and logic models (see Figure 1). The philosophical assumption of pragmatism and mixed methods methodology were used to construct the conceptual framework for this study and incorporated key elements as described by Creswell ${ }^{[17]}$ and Antonenko: ${ }^{[16]}$

- Theoretical perspective: Select a theoretical perspective which best suits the proposed mixed methods study.

- Implementation: The current study adopted a sequential explanatory mixed methods design, which commenced with data collection and analysis from a quantitative phase, followed by data collection and analysis from a qualitative phase.

- Stage of integration: Integrating quantitative and qualitative phases occurred at three levels: design, data collection, and data interpretation and reporting.

- Priority: Quantitative and qualitative phases had equal priority as both are equally informed to address the research questions. 


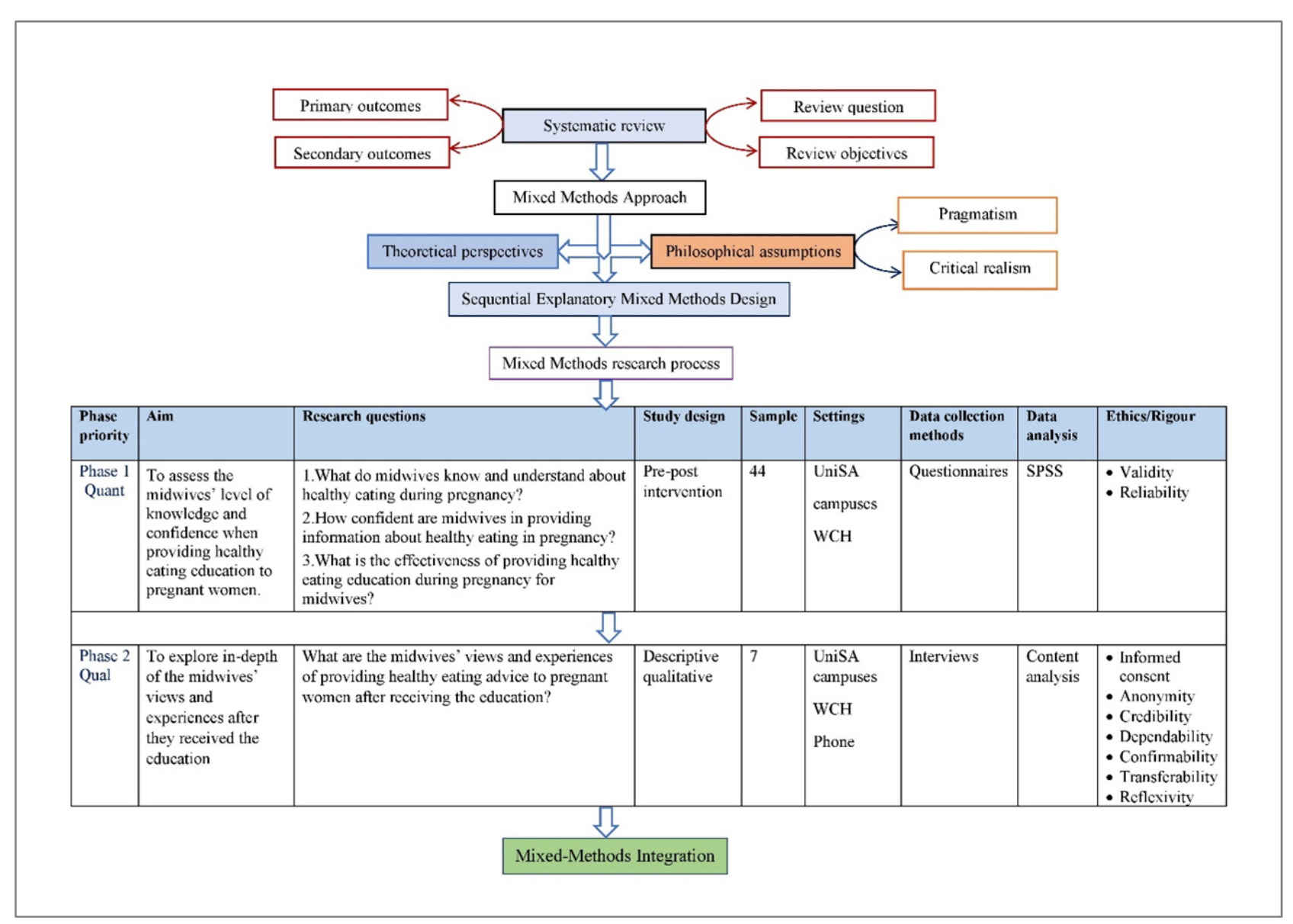

Figure 1. The conceptual framework elements for mixed methods approach

2.2 Implementing research integrity and ethical considerations in designing and conducting the study

It is essential to establish high-quality research throughout the research process. To ensure research integrity and the research process is followed, the mixed methods study adopted rigorous measures during the design, methods, implementation, interpretation and reporting stages of the study. These measures helped the researchers to undertake a well-designed study and reduce the risk of research biases. Following the analyses of quantitative and qualitative data, it is important to integrate the data and create meta-inferences to complete a mixed methods data analysis and interpretation of the combined data. Therefore, meta-inferences were generated from the sequential quantitative and qualitative methods data. This process is in alignment with the recommendations for a mixed method study design. Meta-inferences were derived from integrated quantitative and qualitative methods and data; conclusions were drawn from the combined methods and data (which addresses validity and credibility of the study design. ${ }^{[7]}$

All phases of the research process addressed ethical con- siderations, written permission, verbal and written consent, anonymity and confidentiality, voluntary participation and withdrawal. In addition, the research process addressed recruitment strategies, identified participants, type of data to be collected, appropriate sample size, settings, identified recording methods, and data collection and analysis procedures. ${ }^{[7]}$ Separate procedures were used to assess the reliability and validity of the quantitative data and results and the credibility and trustworthiness of the qualitative data and findings.

\subsubsection{Maintaining validity and reliability in quantitative data collection}

In quantitative research, it is important to consider the quality of the collected data and instrument/tools, ${ }^{[18]}$ which is through validity and reliability. In this midwifery study example, validity and reliability of the questionnaire were assessed using a pilot study. Content and face validity were established by inviting a panel of five midwives to comment and give feedback. The feedback was valuable, and after minor amendments, the questionnaire was clear, easy to read and understand. Seven midwives were invited to pilot the questionnaire at two different time points to estimate reliability. 
No difference was observed between midwives' responses (Cronbach Alpha coefficient was higher than 0.8), indicating reliable internal consistency and high accuracy of responses.

Data collection and analysis: Midwives who live and practice in South Australia were invited to participate in the study. Data were collected at three time points (prior to, immediately, and 6-8 weeks after the workshop/webinar) via a semi-structured questionnaire which was developed to assess midwives' level of knowledge and confidence. More information about the development of the questionnaire has been published. ${ }^{[19]}$ Data analysis was undertaken through using Statistical Package for Social Sciences IBM (SPSS) version 25. Descriptive analysis examined the midwives' demographic characteristics, such as age and previous nutrition education. Data relating to the level of knowledge and confidence were analysed using Wilcoxon Signed Rank test to compare the differences through the questionnaires at three time points. Statistical difference was set at $p<.05$. Findings of the quantitative phase have been published separately. ${ }^{[14]}$

\subsubsection{Maintaining credibility and trustworthiness in qual- itative data collection and analysis}

Previous studies have discussed the need to ensure and maintain rigour in qualitative research and suggested five principles and strategies; these principles are credibility, dependability, confirmability, transferability and reflexivity. ${ }^{[20,21]}$ In the study example, these five principles and strategies are summarised in (see Table 1).

Table 1. Summary of principles and strategies to maintain trustworthiness of qualitative data and findings

\begin{tabular}{|c|c|c|}
\hline Rigour principles & Strategies & Current study (measures) \\
\hline \multirow{3}{*}{ Credibility } & $\begin{array}{l}\text { Prolonged } \\
\text { engagement }\end{array}$ & $\begin{array}{l}\text { - Researcher provided the education and conducted interviews } \\
\text { - In-depth interviews with midwives who had received education } \\
\text { - Transcription and data analysis by researcher } \\
\text { - Built trust with participants and immersion into data } \\
\text { - Richness of data }\end{array}$ \\
\hline & Triangulation & $\begin{array}{l}\text { - Data triangulation (midwives worked in different care models, with various level of } \\
\text { experience) } \\
\text { - Investigator triangulation (two researchers carried out data coding, interpretation } \\
\text { decisions made by research team) }\end{array}$ \\
\hline & Member checking & $\begin{array}{l}\text { - } \text { Content analysis } \\
\text { - No sensitive information obtained from participants } \\
\text { - Member checking during interview, clarification and examples provided to confirm } \\
\text { meaning } \\
\text { - Two researchers conducted data analysis } \\
\text { - The research team revised and discussed interpretations with a final agreement }\end{array}$ \\
\hline $\begin{array}{l}\text { Dependability and } \\
\text { Confirmability }\end{array}$ & Audit trail & - All steps and procedures were described, and study protocol was published. \\
\hline Transferability & $\begin{array}{l}\text { In-depth } \\
\text { description }\end{array}$ & $\begin{array}{l}\text { - Sufficient sample size and settings } \\
\text { - A clear description of data collection and analysis } \\
\text { - Detailed description of participants characteristics, views and experiences with quotes } \\
\text { - Discussing findings and interpretations } \\
\text { - Recommendation for future research }\end{array}$ \\
\hline Reflexivity & $\begin{array}{l}\text { Critical self- } \\
\text { reflection } \\
\text { Critical appraisal }\end{array}$ & $\begin{array}{l}\text { - Maintain the balance between researcher and research relationship } \\
\text { - Re-listened to audio recordings to self-judge the content of the interview } \\
\text { - A co-author listened and checked for leading questions or bias }\end{array}$ \\
\hline \multirow{3}{*}{$\begin{array}{l}\text { Reliability for } \\
\text { content analysis }\end{array}$} & Stability & $\begin{array}{l}\text { - Results were checked several times for coding categories to confirm accuracy } \\
\text { - Similar findings in different codes were merged }\end{array}$ \\
\hline & Reproducibility & $\begin{array}{l}\text { - One co-author conducted independent data analysis, reproduced and reached } \\
\text { agreement with findings and codes }\end{array}$ \\
\hline & Accuracy & $\begin{array}{l}\text { - The primary researcher checked for accuracy } \\
\text { - Co-authors conducted cross-checking transcripts with audio records }\end{array}$ \\
\hline
\end{tabular}

Follow up interview and analysis: Midwives who attended the healthy eating workshop/webinar were invited to partic- ipate in a follow-up semi-structured interview after 6 to 8 weeks. A purposive sample of seven midwives consented 
to participate and were interviewed (six face-to-face, one by telephone). The interviews were audio-recorded and ranged from 25-45 minutes in length. Interviews were conducted by the primary researcher in a private room at University of South Australia (UniSA), and/or Maternity Hospital (Women's and Children's Hospital [WCH]), Adelaide. An interview schedule was utilised, and qualitative descriptive design was undertaken to explore midwives' views and experiences. Eleven open-ended questions were designed to explore and gain an in-depth understanding of midwives views and experiences when providing healthy eating education to pregnant women, including education for vegan and vegetarian diets and cultural food preferences. All interviews were transcribed verbatim. Data were analysed using conventional content analysis ${ }^{[22]}$ through an inductive approach, including open-coding, creating main categories and abstractions. Detailed findings of the qualitative phase have been published separately. ${ }^{[23]}$

\section{INTEGRATION OF QUANTITATIVE AND QUALITATIVE DATA}

\subsection{Data integration and interpretation of mixed meth- ods studies}

Data integration is an essential process and innovative approach in mixed methods research analysis and conceptualisation of phenomena. ${ }^{[24]}$ Integration of data combines quantitative results and qualitative findings, which enables a more in-depth understanding of data. ${ }^{[24-26]}$ Data integration strengthens the value of mixed methods research and reduces the single approach weakness. ${ }^{[7,25]}$ Integration can occur throughout the research process, starting from formulating the research aims, objectives and continuing with design, procedures, analysis and findings. ${ }^{[27]}$ The main purposes of data integration are 1) illustration, 2) convergent validation and 3) development and achievement of the richness of data. These purposes place the results from different methods into a dialogue which brings the research topic alive. ${ }^{[24,28]}$

Data analysis integration and presentation lead to coherence of the quantitative results and qualitative findings with three expected outcomes: 1) confirmation occurs when findings from both types of data confirm results of the other type, 2) expansion when the findings from two sources are different and expand on various insights and address different aspects, 3) discordance which occurs when findings from two data sets are inconsistent and contradict each other; however, it is still important to explore differences. ${ }^{[25,29]}$

Achieving integration is the desired goal for mixed methods design, but sometimes cannot be applicable in practice. A newly proposed alternative to data integration is data diffrac-

Published by Sciedu Press tion. ${ }^{[30]}$ Data diffraction offers an innovative approach when using mixed methods and provides a creative way to respond to research questions. This approach may allow data to cohere or not, which demonstrates the on-going nature of research with no clear endpoint and produces different visibilities that cannot be integrated into a single narrative format. ${ }^{[30]}$

\subsection{Data integration principles and methods}

The study example achieved data integration through utilising an explanatory sequential mixed methods design at all research stages - namely, integration during study design, methods, and interpretation and reporting levels.

\subsubsection{Integration at study design level}

Integration at study design was achieved through adopting the explanatory sequential design, which commenced with quantitative data (Phase 1), followed by qualitative data (Phase 2). This study design was based on the systematic review findings, which highlighted a dearth of mixed methods design studies for the topic of interest. Therefore, this design was chosen as no other studies have used this research approach and methodology for the topic and integration would provide a richer/deeper understanding of midwives' knowledge and confidence to provide healthy eating education.

\subsubsection{Integration at methods level}

Integration at methods and procedures level as described by Fetters, Curry ${ }^{[25]}$ was achieved by using the following three approaches of integration:

1. Connecting through sampling where participants from Phase 1 continued to participate in Phase 2.

2. Building was by ensuring results from Phase 2 built on Phase 1 findings, which provided more explanations to bridge the research gap.

3. Merging the two datasets for analysis after analysing each phase or dataset separately.

\subsubsection{Integration at interpretation and reporting level}

Maintaining a high-quality analysis for mixed methods during data integration is a challenge as generating trustworthy meta-inferences as general conclusions can be difficult. ${ }^{[31]}$ Therefore, integration of data should consider other potential validity issues that arise. ${ }^{[7,24,31]}$

During data analysis, 'following a thread' technique was utilised. Following a thread commences with data analysis of each component to identify key findings and questions that require additional exploration; then this thread is followed in a form of a theme or a question from one data set, emerging across other components. ${ }^{[26]}$ In this study example, this thread technique, based on midwives' responses 
involved matching quantitative questions from a questionnaire that included open questions to the interview questions (see Appendix 1). Another technique used was 'extreme case analysis' in which analysis of one data set is continued to the other data set to identify extreme cases. ${ }^{[32]}$ This was achieved by using high and low extreme cases to represent a positive correlation between midwives' level of knowledge and confidence (see Figure 2).

Data integration at the interpretation and reporting level involved presenting the main findings from quantitative and qualitative data side-by-side or theme-by-theme using a 'weaving technique' and reporting these findings in a narrative form. ${ }^{[25,28]}$ Joint displays were used to identify new insights from the combined data, and further information was obtained from this collective quantitative and qualitative data to provide a broader and more comprehensive interpretation of participants' responses and the research problem. ${ }^{[25,28]}$ In this study example, the researchers arranged data in figures, tables and matrices. ${ }^{[25,33]}$ A comparison of findings can provide a holistic picture of the research topic and recommendations for future research, practice and educational policy. ${ }^{[7,32]}$

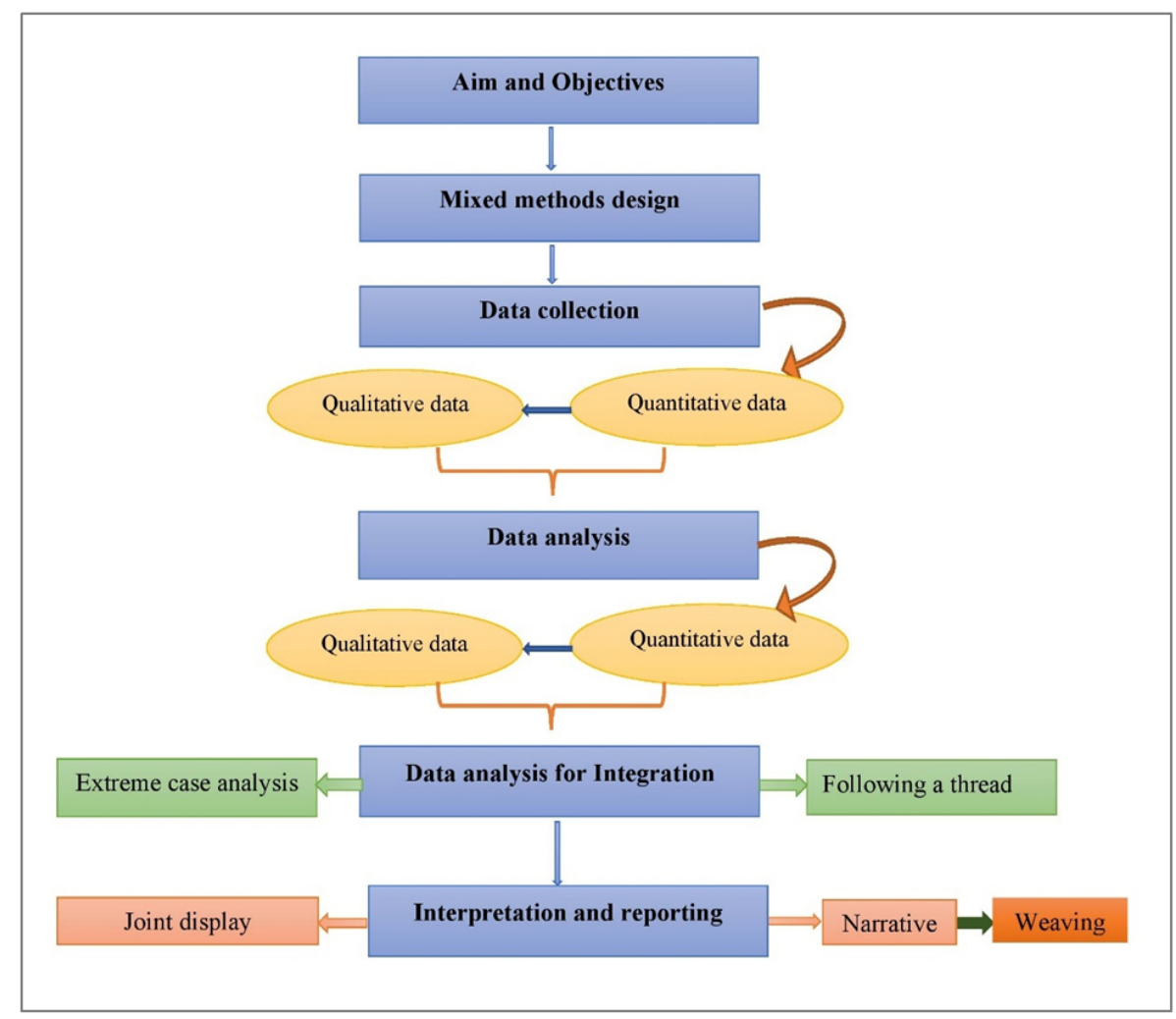

Figure 2. The study example techniques for data integration process

3.3 Examples of Data Integration: "investigated and ex- 2 . plored midwives' levels of knowledge and confidence to provide healthy eating education for pregnant women."

Findings from pre-, immediate, post-follow-up questionnaire data were integrated with midwives' responses during the interviews. These integrated findings are presented as 1) midwives' level of knowledge, 2) midwives' level of confidence, 3) midwives' total knowledge and confidence scores, and 4) scope of practice and public health education role.

\subsubsection{Midwives' level of knowledge}

The main integrated themes from the two datasets related to the midwives' level of knowledge are summarised in Table

\section{A. Previous nutrition knowledge and need for Continual Professional Development (CPD)}

Quantitative: Midwives' previous nutrition knowledge: Nearly half of the midwives $(n=21,47.7 \%)$ reported they received previous nutrition education either during their undergraduate studies or post-registration training. Only three out of 44 midwives applied for CPD education related to women's nutrition over the previous 12 months.

Qualitative: Need for CPD education: Midwives acknowledged their low level of knowledge on specific topics. They reported they 'struggled' with women with specific dietary 
requirements such as vegans and vegetarians and cultural food preferences and needed CPD education.

Outcomes: The quantitative data only provided information about the percentage of midwives who received previous nutrition education and who applied for CPD. The qualitative data provided details and expanded on midwives' level of knowledge and how their undergraduate education and post-registration training affected their level of nutrition education.

Discussion: This combined data reported that some midwives lacked current nutrition education. Similarly, previous studies have reported that midwives lacked the development of nutrition assessment and practical skills to provide nutrition advice to pregnant women. ${ }^{[34]}$ This lack of practical and theoretical skills requires undergraduate curriculum review and regular updates according to the requirements of student midwives' needs. A recent study on midwives nutrition education in Australia ${ }^{[34]}$ reported that more than
$51.1 \%(168 / 329)$ of participants received nutrition education during undergraduate studies and 54.1\% (178/329) postqualification. Providing CPD education is important to improve and maintain the midwives' knowledge, skills and level of proficiency to provide best-practice care. ${ }^{[35]}$ The CPD responsibility should be shared between midwives and their employer. ${ }^{[36]}$ Barriers were reported that prevented midwives from receiving CPD such as lack of funding and cost, lack of support from the employers, lack of internet access (especially for remote areas), and personal factors such as limited time and lack of support for childcare. ${ }^{[37]}$ Addressing these barriers require collaboration between employees and their employers.

Implications: Provide healthy eating education according to the evidence-based guidelines to improve midwives' knowledge regarding vegans, vegetarians, and cultural food choices to be included within undergraduate and post-registration education.

Table 2. Joint displays comparing results and outcomes for midwives' level of knowledge

\begin{tabular}{|c|c|}
\hline Joint display of the integrated quantitative and qualitative data & Outcomes \\
\hline $\begin{array}{l}\text { A) Midwives' previous nutrition knowledge and need for CPD } \\
\text { Nearly half }(\mathrm{n}=21,47.7 \%) \text { of midwives received previous nutrition education either during their } \\
\text { undergraduate study or post-qualification training. } \\
\text {...having come to your talk a few weeks ago that will probably change a lot of the information... it [healthy } \\
\text { eating program] made me really more aware. Particularly with the vegan women... making sure... we give } \\
\text { them the right advice on supplements as well... being aware of... the resources of where they can go and } \\
\text { get that right correct information [MW6]. }\end{array}$ & Expansion \\
\hline $\begin{array}{l}\text { B) Significant change in midwives' nutrition knowledge } \\
\text { A highly statistically significant difference of total knowledge scores between pre, and immediate } \\
\text { questionnaires }(p<.001) \text {, and immediate with post-questionnaires }(p<.001) \text {. } \\
\text { I always knew my limitations and capabilities like you know the specific real values and things of what to } \\
\text { advise with and... I had a very good general knowledge, but not specific knowledge... after doing the } \\
\text { webinar I have realised how much I didn't know..., I still feel that I do not know.... we're very good at } \\
\text { giving general advice, but when it comes to specific milligrams per day and all those kinds of things... } \\
\text { perhaps we're flat out at remembering iron, folic acid and now iodine as well... it's very specific [MW5]. }\end{array}$ & $\begin{array}{l}\text { Confirmation/ } \\
\text { Expansion }\end{array}$ \\
\hline $\begin{array}{l}\text { C) Midwives nutrition information sources and hospital materials } \\
\text { More than three quarters ( } \mathrm{n}=32,78 \%) \text { of midwives using general knowledge followed by midwifery } \\
\text { education ( } \mathrm{n}=23,56.1 \% \text { ) and governmental websites ( } \mathrm{n}=20,48.8 \%) \text {. } \\
\text {... I don't think that the dietary information was as extensive in the written information when we would talk } \\
\text { to them....I don't know that we are giving them really extensive advice in written information, so I don't } \\
\text { think we're giving them enough [MW6]. }\end{array}$ & Discordance \\
\hline $\begin{array}{l}\text { D) Midwives experiences and views of using guidelines } \\
\text { Majority of midwives ( } \mathrm{n}=37,84.1 \%) \text { perceived that they could benefit from using specific guidelines. } \\
\text {...I didn't even know that there were actual guidelines, I've never looked at those... some of those } \\
\text { brochures I'm going to use in my private practice definitely, because I think they're really clear with the } \\
\text { way they describe what a healthy diet should be, and how much portions and serves in those sort of things } \\
\text { that, the pregnant women should be eating [MW7]. }\end{array}$ & Discordance \\
\hline
\end{tabular}


B. Significant change in midwives' nutrition knowledge Quantitative: Significantly improved level of knowledge: Midwives' level of nutrition knowledge was assessed at three time points. The Wilcoxon Signed-Rank test showed a highly statistically significant difference of total knowledge scores between pre-, and immediate questionnaires $(p<.0001)$ and immediate with post-questionnaires $(p<.0001)$, where the level of knowledge was low before attending the education.

Qualitative: Limited nutrition knowledge before the education: Some midwives reported a low level of knowledge before attending the workshop/webinar, which improved after attending the education.

Outcomes: The quantitative data showed that midwives' level of nutrition knowledge significantly improved after attending the education. The qualitative data confirmed these findings and provided details of midwives' level of knowledge before and after the education.

Discussion: The findings highlighted that nearly half of the midwives had limited knowledge for daily energy requirements, water intake, iodine requirements, omega- 3 and vitamin D requirements before attending the education, whereas, this was improved after the education. ${ }^{[14]}$ Similarly, previous studies reported that midwives have inadequate nutrition knowledge ${ }^{[13]}$ in several areas, including weight gain, dairy serves and iodine requirements. ${ }^{[34]}$ However, limited nutrition knowledge significantly improved after attending nutrition education. ${ }^{[38]}$ Furthermore, midwives in the current study, still require education about vitamin D and omega-3. Similarly, other studies have shown that health professionals had a low engagement with pregnancy nutrition issues, especially iodine, omega-3 and fish consumption. ${ }^{[39]}$ They acknowledged the need for on-going nutrition education related to iodine recommendations. ${ }^{[39,40]}$

Implications: Provide healthy eating education based on evidence-based guidelines, and ensure midwives adhere to national updated recommended guidelines.

\section{Midwives' nutrition information sources and hospital materials}

Quantitative: Nutrition information sources: Midwives used various sources of information to provide education to pregnant women, such as own general knowledge followed by undergraduate midwifery education and government websites.

Qualitative: Educational materials used by midwives: Most midwives reported they used the available resources at their place of employment, i.e. brochures, pamphlets, information sheets or browsing websites when providing healthy eating education, and/or their general knowledge. How- ever, some midwives described these resources as descriptive and not comprehensive enough to educate pregnant women. The content analysis of open-ended questions confirmed that midwives usually used the most commonly available brochures at the hospital and government websites such as South Australian prenatal practice guidelines https://www.sahealth.sa.gov.au/

Outcomes: Quantitative results identified the main information sources which midwives used to provide education for pregnant women. Qualitative data highlighted more details of information sources which indicated a discordance between the quantitative and qualitative data.

Discussion: There is a limited exploration of information sources that midwives have used to provide nutrition education. Most midwives felt conflicted because the available resources in their workplace were descriptive and not comprehensive. The combined data highlighted that the common information sources being used were general knowledge, midwifery education and government websites. Similarly, Elias and Green ${ }^{[41]}$ reported that midwives' sources of nutrition information were: nutrition organisations, general knowledge and midwifery education. Arrish, Yeatman ${ }^{[34]}$ reported that the most common information was from health professionals, general knowledge followed by midwifery education.

Policy implications: The workplace should provide education and resources for midwives on topics for healthy eating based on the most recent evidence-based guidelines.

\section{Midwives' experience and views of using healthy eat- ing guidelines}

Quantitative: Benefit of guidelines: Before the education (workshop/webinar), the majority of midwives $(n=37$, $84.1 \%$ ) reported they would benefit from using specific guidelines to provide nutritional advice to pregnant women. After attending the education, all participants reported they would benefit from nutritional guidelines.

Qualitative: Midwives using guidelines: Before the education, most midwives reported they did not refer to guidelines because they did not know about the existence of guidelines, or they did not trust or like guidelines. However, after attending the education, they reported using the provided guidelines at their workplace. The open-ended responses showed that most midwives looked for consistent, comprehensive and accurate nutrition information based on most recent guidelines.

Outcomes: Quantitative data confirmed that midwives would benefit from guidelines, while qualitative data indicated that most of the midwives did not use available guidelines. Mid- 
wives started using the provided resources after education. Overall, discordance between quantitative and qualitative data may require further exploration.

Discussion: The combined findings identified that few midwives referred to the national healthy eating guidelines, which is consistent with a previous study. ${ }^{[42]}$ Some midwives lacked awareness of the availability of nutrition guidelines during pregnancy which suggested a need for access to standardised resources and accurate, evidence-based guidelines. This finding is similar to a previous study ${ }^{[42]}$ which recommended better funding for standard information and resources. Lack of resources was identified in an earlier a study ${ }^{[43]}$ which reported a lack of clear guidelines in the workplace was a reason why $15 \%$ of midwives did not adequately discuss nutrition education with pregnant women. Similarly, a New Zealand study reported that the most commonly used resources by midwives were guidelines designed by Ministry of Health. ${ }^{[41]}$

Implications: Maternity services and professional bodies need to ensure the availability of consistent, comprehensive and up-to-date healthy eating guidelines for workplaces. $\mathrm{Fu}$ ture research is needed to explore the available resources and guidelines used by midwives.

\subsubsection{Midwives' level of confidence}

The integrated themes from the questionnaires and interview responses related to the midwives' level of confidence are summarised in Table 3.

\section{A. Significant improved midwives' level of confidence Quantitative: Midwives' level of confidence: The Wilcoxon} Signed Rank test showed a statistically significant difference of midwives' total confidence between the pre- and immediate questionnaires, and immediate with post-questionnaires. Before education, midwives were not confident to provide education for vegan/vegetarian pregnant women. After attending the education, confidence improved to 'moderately confident' and remained the same at 6-8 weeks.

Qualitative: More awareness and confidence in providing healthy eating education: Before the education, midwives struggled with specific dietary requirements. After the education, all participants became more confident to talk about diet for vegan/vegetarian pregnant women.

Outcomes: The quantitative data showed that midwives' level of confidence was low before the education, with confidence improved and maintained after the education. Qualitative findings confirmed that midwives became more confident and aware of providing education to pregnant women, particularly, vegan and vegetarian women.

Published by Sciedu Press
Discussion: The combined data showed significant improvement in midwives' level of confidence to discuss healthy eating education for vegan and vegetarian pregnant women, which is dissimilar to a previous study which reported that midwives have a high level of confidence to provide education about nutrition during pregnancy. ${ }^{[41]}$ Midwives increased their confidence to discuss general healthy eating and also guidance for folic acid, iodine and vitamin supplementations. However, midwives needed more education for omega-3 and vitamin D. Similarly, Soltani, Duxbury ${ }^{[43]}$ have reported that midwives were confident to provide education regarding folic acid, iron supplements, alcohol and caffeine intake, but less confident to discuss omega-3, multivitamins and vitamin $\mathrm{D}$.

Implications: In-service education and training for midwives is needed, especially for those working in antenatal clinics or midwifery group practice and/or provide antenatal education.

\section{B. Midwives' perceived role in providing nutrition edu- cation}

Quantitative: Midwives' perception about the importance of nutrition education: Across the three questionnaires, the majority of midwives perceived that providing nutrition education during pregnancy is very important. However, only two thirds $(n=27,61.4 \%)$ self-rated their role in providing nutrition education as very important.

Qualitative: Midwives' perceived role and influence: Most midwives perceived that they have a vital role when providing healthy eating education as they are the main source of information. However, they were limited by several barriers, such as pregnant women's motivation and level of education and midwives' awareness of their role.

Outcomes: Quantitative data provided details about midwives who self-rated their role as very important, and qualitative data explored those midwives who self-rated their role as very important. This outcome implies an expansion of the midwives' role and details barriers that midwives may have when providing healthy eating education to pregnant women.

Discussion: The data identified a lack of midwives' awareness about their role and lack of education to improve and maintain their level of knowledge and confidence. Similarly, previous studies have reported that the midwives' role was not aligned with their clinical practice and advice given was passive and medically-based. ${ }^{[34,42]}$ However, some midwives reported that they have an important role during antenatal appointments, which is similar to a study undertaken in Sweden. ${ }^{[4]}$ This Swedish study reported midwives to have a unique role in providing healthy eating education for pregnant women at antenatal appointments. However, 
midwives in the study example reported many barriers that hindered them from providing specialised nutrition advice and reported a need for further support and training in specific nutrition-related topics, which is similar to findings of Garnweidner, Sverre Pettersen. ${ }^{[45]}$

Implications: Regulatory, accreditation and professional bodies need to provide clear definitions, such as the International Confederation of Midwives' (an accredited non-government organisation representing midwives and midwifery organisations worldwide) to clarify the midwives' role to provide healthy eating education to pregnant women and need for on-going education.

C. Education for cultural food preferences of ethnic minorities

Quantitative: Low confidence to discuss cultural food choices: Midwives level of confidence improved from 'slightly confident' to 'confident' and remained improved at $6-8$ weeks.

Qualitative: Struggle with lack of resources: Most midwives struggled to provide education for cultural food preferences of ethnic minorities due to: limited knowledge and confidence to provide education for these women, lack of resources, language barriers, traditions and women resistance to change.

Outcomes: Quantitative findings showed an increase of midwives' level of confidence to provide education for cultural food preferences after education. Qualitative data identified reasons for midwives' low level of confidence and limited knowledge to provide healthy eating education for pregnant women from different cultures before attending the education.

Discussion: The data highlighted that midwives have a low level of confidence to provide nutrition education for pregnant women from diverse cultures and reported barriers such as differences in language, resources and traditions hindered them from fulfilling this role. Midwives reported a need for additional resources to provide nutrition education for women from diverse cultures. This finding is similar to what has been previously reported by Lucas, Charlton ${ }^{[46]}$ that Aboriginal and migrant women have different cultural needs, and language barriers can inhibit the provision of healthy eating education. Some midwives perceived that pregnant women from diverse cultures were eating healthily. However, this perception is inconsistent with previous literature which reported these groups of women to need more education. ${ }^{[46,47]}$ Furthermore, ethnic minorities women may have an increased risk for poor dietary habits related to lowincome, and they do not sustain the nutrition requirements for pregnancy, ${ }^{[47]}$ indicating that they require more counselling. Educational materials provided for pregnant women should be carefully assessed for content and be provided in a language which is suitable for culturally and linguistically diverse women. ${ }^{[48]}$

Implications: Maternity services and midwives have a responsibility to maintain up-to-date education and training on all aspects of healthy eating, including cultural food preferences and ethnic minorities. Education may be enhanced by utilising trained health professionals from diverse cultures.

\section{Health professionals who are assessing nutritional sta- tus}

Quantitative: Who is responsible? Most midwives ( $\mathrm{n}=32$, $72.7 \%$ ) perceived themselves the key person responsible for assessing the nutritional status of pregnant women; however, some midwives $(n=9,20.5 \%)$ considered dietitians the most responsible.

Qualitative: 'I need to go and get some advice': Midwives have the essential knowledge to provide healthy eating education, yet they refer women who need advanced education to a dietitian. The referral was for many reasons such as midwives' limited knowledge and confidence to discuss complex conditions such as overweight, eating disorders and medical conditions. Content analysis responses showed that the health professional who sees women regularly or the primary carer is responsible for providing this information.

Outcomes: Both data have discordance and diffraction. The quantitative data demonstrated that midwives perceived themselves responsible for pregnant women; however, the qualitative data showed that most midwives felt they only had basic knowledge and would refer women with complex conditions to dietitians.

Discussion: Midwives are one of the three influential health professionals (including general practitioners and obstetricians) who provide healthy eating education for pregnant women ${ }^{[49]}$ this is despite these health professionals reporting limited opportunities to access continuing healthy eating education. The current study showed that most midwives perceived themselves as the first point of contact for pregnant women to undertake a nutrition assessment. Similarly, Arrish, Yeatman ${ }^{[42]}$ reported that midwives are the first point of contact who provides general nutrition advice. In contrast, dietitians provide advanced nutrition advice for specific and complex medical conditions, whereas ${ }^{[46]}$ reported that general practitioners were the first point of contact during early pregnancy.

Implications: All health professionals should adopt evidencebased healthy eating guidelines, and awareness needs to be 
raised about the importance of multidisciplinary collaboration between health professionals when providing nutrition education to pregnant women to ensure appropriate referral when appropriate.

E. Midwives referral to dietitians Quantitative: Availability of dietitians' services: Most midwives $(n=37,84.1 \%)$ had access to dietitians' services and nutrition support for pregnant women at their workplace; and, more than twothirds of midwives referred to dietitians.

Qualitative: Which conditions require a referral? Most midwives provide general healthy eating education to pregnant women during antenatal appointments and referred women with complex medical conditions such as gestational diabetes, high body mass index, and specific dietary requirements, i.e. vegans and vegetarians. The open-ended responses showed most midwives listed the common conditions they refer to dietitians which were similar to the qualitative findings.

Outcomes: Qualitative data provided further explanation of common conditions midwives referred to dietitians.

Discussion: The data showed that midwives provide general healthy eating education at antenatal clinics. The most common conditions midwives referred to dietitians were similar to Arrish, Yeatman. ${ }^{[34]}$ A few midwives highlighted that referral and availability of dietitians' services were restricted and only offered for women with diabetes, especially in remote areas. Other reasons for not referring to dietitians included limited funding and time for midwives, which is similar to. ${ }^{[34]}$ According to current guidelines, health professionals should discuss nutrition and provide advice to pregnant women at every antenatal appointment, conduct maternal nutrition assessments and refer when appropriate. To achieve this, midwives require additional support to provide pregnant women with individualised and holistic nutrition education. ${ }^{[42]}$

Implications: Strategies are required to support midwives to obtain CPD to provide effective healthy eating education to women and address barriers for referral.

In summary, data integration has shown where quantitative and qualitative data are consistent or have a discordance. A summary of these integrated findings are presented using a joint display to compare both findings, and the expected outcomes developed $^{[29]}$ (see Table 3).

Table 3. Joint displays comparing results and outcomes for midwives' level of confidence

\begin{tabular}{|c|c|}
\hline Joint display of the integrated quantitative and qualitative data & Outcomes \\
\hline $\begin{array}{l}\text { A) Significant improved midwives' level of confidence } \\
\text { Wilcoxon Signed Rank test showed a statistically significant difference for midwives' total confidence score } \\
\text { between pre and immediate questionnaires, immediate and post-questionnaires. } \\
\text {...I'm coming across a lot more women who are maybe vegan and vegetarian, and you know, and you come to the } \\
\text { iron levels, and they're talking about iron infusions and things you just wonder whether they're necessary, and so } \\
\text { yes... I feel maybe more confident to talk a bit more about that now [MW2]. }\end{array}$ & $\begin{array}{l}\text { Confirmation/ } \\
\text { Expansion }\end{array}$ \\
\hline $\begin{array}{l}\text { B) Midwives perceived role in providing nutrition education } \\
\text { Most midwives across three questionnaires, perceived providing nutrition education during pregnancy as very } \\
\text { important. } \\
\text { [My role is] very hit and miss... I think my influence on them is ... depending on the situation and how motivated } \\
\text { they are... but it's also a little bit of insight, often I think people just do not have the insight into knowing what } \\
\text { lifestyle choices they've take? [MW5]. }\end{array}$ & Expansion \\
\hline $\begin{array}{l}\text { C) Education for cultural food preferences and ethnic minorities Midwives' level of confidence for providing } \\
\text { education re: cultural food choices, and education for ethnic minorities groups improved from 'slightly confident' (n } \\
=18,40.9 \%) \text {, ( } \mathrm{n}=14,31.8 \% \text { ) to "confident" and remained improved at } 6-8 \text { weeks. } \\
\ldots \text { that might be lacking a little bit still so more resources on that [cultural food preference]and... not just in their } \\
\text { language but in their foods as well ... language barriers... women in your multicultural societies, ... Tradition ... } \\
\text { Change is a barrier in itself getting people to change their views, their opinions on thing ... [MW1]. }\end{array}$ & Expansion \\
\hline $\begin{array}{l}\text { D) Health professionals who are assessing the nutritional status } \\
\text { Most midwives ( } \mathrm{n}=32,72.7 \%) \text { perceived themselves as key person for assessing the nutritional status of pregnant } \\
\text { women. } \\
\text { I've got the very basic knowledge about nutrients levels but when it comes to other complexes, I would not hesitate } \\
\text { to go okay; this person really should go and see a dietitian, for example, an overweight [MW4]. }\end{array}$ & Discordance \\
\hline $\begin{array}{l}\text { E) Midwives referral to dietitians } \\
\text { More than two thirds of midwives refer pregnant women to dietitians } \\
\text { I often refer them [vegans/vegetarians] on to a dietitian because I would not feel comfortable in knowing how to } \\
\text { advise them on their balanced diet with their increased pregnancy needs, so mostly we'll talk about the increased } \\
\text { needs, and mostly we'll talk about how it affects your baby, but it also really affects you as well [MW5]. }\end{array}$ & Expansion \\
\hline
\end{tabular}




\subsubsection{Midwives' total knowledge and confidence scores}

Quantitative: Correlation between midwives' level of knowledge and confidence: Extreme case-analysis has been used to clarify the relationship between midwives' level of knowledge and confidence (see Appendix 2).

Qualitative: Qualitative findings indicated a further exploration of midwives needs.

Discussion: Quantitative results showed a positive association between midwives' level of knowledge and confidence, while qualitative data indicated the necessity of regular exploration of midwives' needs when providing nutrition education. The participants who had a low score indicated that some midwives still require general and advanced healthy eating education.

Implications: Regular assessment of midwives' education needs is required to improve and maintain their level of knowledge and confidence to provide healthy eating education for pregnant women.

\subsubsection{Scope of practice and public health education role}

This section is an elaboration on the significant unexpected findings from quantitative results or qualitative findings. In the absence of available qualitative data, a significant quantitative finding (Midwives' confidence to provide education for dental care) couldn't be integrated. Additionally, in the absence of available quantitative data, some significant qualitative findings (Models of care, and Midwives' perception of pregnant women's level of education), these findings couldn't be integrated.

\section{A. Midwives' confidence to provide education for dental care}

Quantitative findings: Low confidence to provide education for dental care: Midwives' level of confidence to provide education for dental care during pregnancy improved from 'not confident at all' and 'slightly confident' $(\mathrm{n}=12,27.3 \%)$ before attending the education, to 'moderately confident' (n $=13,44.8 \%$ ) immediately after the education and remained the similar $(\mathrm{n}=7,36.8 \%)$ at $6-8$ weeks.

Qualitative: No qualitative data was collected and analysed related to dental care from the study example.

Outcomes: These findings showed that midwives need education related to dental care based on evidence-based guidelines.

Discussion: No qualitative findings exist to clarify midwives' experiences of providing healthy eating education related to dental care during pregnancy. Quantitative results showed that midwives who responded to the survey had a low level of knowledge and confidence to provide oral health education. Similarly, a previous study ${ }^{[50]}$ reported that midwives were unaware of poor oral health effects for pregnant women and her developing baby. Another study reported midwives' level of knowledge varied when providing education about dental diseases, and only a few $(n=79 / 947,8.4 \%)$ discussed associations between periodontal diseases and perinatal complications. ${ }^{[51]}$ Midwives have reported several barriers when discussing oral health care, such as lack of knowledge and confidence to discuss this topic, limited time and lack of appropriate referral and access to public dental services. ${ }^{[50,52]}$ According to the international guidelines and scope of practice, ${ }^{[53]}$ midwives' role should include an oral health assessment at every antenatal appointment. Midwives in Australia, however, are not educated to undertake this role. ${ }^{[54]}$

Implications: Include guidelines related to dental care during pregnancy at workplaces. Regulatory, accredited, professional bodies recommend allocating more time for midwives at antenatal appointments to provide oral health education and assessment.

\section{B. Models of care}

Quantitative: No quantitative data was collected and analysed related to models of care from the study example.

Qualitative findings: Midwives worked in different models of care which reflect different practices within their workplace.

Discussion: No quantitative findings from the study example to clarify midwives' experiences of providing healthy eating education related to models of care during pregnancy. Midwives reported that continuity of care is the best model of care in which they can build a trusting relationship with pregnant women. These findings are consistent with previous findings ${ }^{[42,55]}$ which reported that women who have access to continuity of care had improved clinical outcomes and positive relationships with midwives. Midwives acknowledged that within the continuity of care model, they have more time to discuss nutrition education and provide personalised advice. Similarly, ${ }^{[42]}$ reported a trusted relationship with pregnant women within the continuity of care models enabled more time allocation to provide detailed nutrition advice. In the study example, midwives reported limited access and availability of continuity of care models for most pregnant women.

Implication: Maternity services to allocate more time and resources for midwives in different models of care to enable them to provide advanced and focused nutrition education 
for all pregnant women.

\section{Midwives' perception of pregnant women's level of education}

Quantitative: No quantitative data was collected and analysed related to midwives' perception of pregnant women's level of education from the study example.

Qualitative findings: Midwives claimed that some pregnant women are well-educated and motivated to seek nutrition education from different sources.

Discussion: Wall, Gammon ${ }^{[56]}$ reported that a high level of education was associated with a high score of healthy diet during pregnancy; this confirmed midwives' claim that some pregnant women are well-educated and motivated to seek nutrition education. In contrast, a low level of education was associated with a poor score of a healthy diet during pregnancy. Other studies ${ }^{[57,58]}$ have reported women to be motivated to achieve behavioural changes to their diet during pregnancy. Several strategies have been suggested to promote healthy eating behaviours to pregnant women such as ensuring health professionals provide evidence-based advice on healthy eating during appointments, ${ }^{[59]}$ availability of nutrition education resources, in-service training ${ }^{[60]}$ and increasing public and medical awareness of healthy eating

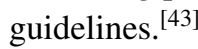

Implications: Raise health professional and public awareness of the importance of nutrition education and need to adopt a healthy eating lifestyle during pregnancy.

\section{Conclusions}

4.1 Achieving data integration "investigated and explored midwives' levels of knowledge and confidence to provide healthy eating education for pregnant women."

The key conclusions from the study example which investigated and explored midwives' level of knowledge and confidence to provide healthy eating education for pregnant women, in which a mixed methods research design was used are: This example illustrates the use of a sequential explanatory mixed methods design in which quantitative and qualitative data were collected and analysed separately and sequentially. Quantitative results provided information about midwives' level of knowledge and confidence, which improved and was maintained after attending a healthy eating education intervention. Qualitative findings provided details about midwives' views and experiences after attending the healthy eating education, and also identified barriers for midwives in their workplace. This mixed methods approach and study design were used to create comprehensive, integrated datasets of both quantitative results and qualitative findings to provide conclusions about midwives' level of knowledge and confidence to support pregnant women to eat healthily. In this study example, the researchers evaluated different approaches and techniques for achieving integration of data to identify an exemplar way of extending the benefit from undertaking a mixed methods research study.

Conducting a mixed methods study with data collection in two phases is a powerful approach to identify and enhance the study strengths, provide richness of data, and increase validity and trustworthiness of findings. However, some limitations were identified. The sample size was appropriate for the study design for each phase but did not allow for transforming one data set to the other when conducting integration. The small sample size created a risk for participants to be identified when matching cases, and this prevented matching the data for a matrix display.

\subsection{Contribution to mixed methods research}

The design and implementation framework for this study to undertake integration was based on previous frameworks by Antonenko ${ }^{[16]}$ and Creswell. ${ }^{[17]}$ Integration was guided by Fetter et al. ${ }^{[25]}$ and Guetterman et al. ${ }^{[28]}$ Methodological contributions: The study illustrates how integration was undertaken and achieved at all levels of the study (design, methods, analysis, interpretations and reporting). Integration at study design level occurred by integrating quantitative and qualitative datasets utilising explanatory sequential design (quantitative data collection and analysis to inform the follow-up qualitative phase). Integration at methods level was via three ways: connecting (some participants who attended Phase 1 continued to participate in phase two), 2) building (results from Phase 2 built on Phase 1 findings) and 3) merging (findings of two datasets were brought together for meta-analysis). Integration at interpretation and reporting levels occurred through using a narrative approach when quantitative and qualitative data were described sideby-side through a weaving approach, which enabled comparing findings and developing an outcome (meta-inferences). Furthermore, a joint display was used for representing the main findings from both datasets in one display and using extreme case analysis to represent findings. This integration at all levels of the study helped to provide comprehensive conclusions for findings of both datasets and outcomes from comparing both results/findings and future implications.

\section{ACKNOWLEDGeMENTS}

The authors acknowledge Cultural Affairs and Mission Sector, Ministry of Higher education, Egypt funding a schol- 
arship for PhD studies at the University of South Australia. All authors would like to acknowledge and say thank you to midwives who actively participated in the healthy eating education workshops/webinar and interviews, Thank you also to Dr Monica Behrend for her feedback and editing the manuscript

\section{CONFLiCTS OF INTEREST Disclosure}

We wish to confirm that there are no known conflicts of interest associated with this publication.

\section{REFERENCES}

[1] Denzin NK, Lincoln YSE. The Sage handbook of qualitative research,. 3rd ed. Denzin NK, Lincoln YS, editors. Thousand Oaks, CA: SAGE Publications Ltd; 2005.

[2] Teddlie C, Tashakkori A. Foundations of mixed methods research: Integrating quantitative and qualitative approaches in the social and behavioral sciences. Los Angeles: Sage Publications; 2009.

[3] Creswell JW, Plano Clark VL. Designing and conducting mixed methods research. Thousand Oaks, CA: SAGE Publications; 2007.

[4] Greene J. Mixed methods in social inquiry. San Francisco, CA: Jossey-Bass; 2007.

[5] Johnson RB, Onwuegbuzie AJ, Turner LA. Toward a definition of mixed methods research. 2007; 1(2): 112-33. https://doi.org/ 10.1177/1558689806298224

[6] Timans R, Wouters P, Heilbron JJT, et al. Mixed methods research: What it is and what it could be? 2019; 48(2): 193-216. https://doi.org/10.1007/s11186-019-09345-5

[7] Creswell JW, Clark VLP. Designing and conducting mixed methods research. Los Angeles: Sage Publications; 2011.

[8] Kroll T, Neri BA M. Designs for mixed methods research. Mixed Methods Research for Nursing and the Health Sciences. 2009; 31-49 p. https://doi.org/10.1002/9781444316490.ch3

[9] Kwon EJ, Kim YJ. What is fetal programming?: A lifetime health is under the control of in utero health. Obstet Gynecol Sci. 2017; 60(6): 506-19. PMid:29184858 https://doi.org/10.5468/ogs. 2017 .60 .6 .506

[10] Wennberg L, Lundqvist A, Hogberg U, et al. Women's experiences of dietary advice and dietary changes during pregnancy. Midwifery. 2013; 29(9): 1027-34. PMid:23427852 https://doi.org/10.1 016/j.midw.2012.09.005

[11] Arrish J, Yeatman H, Williamson M. Midwives and nutrition education during pregnancy: a literature review. Women and Birth. 2014; 27(1): 2-8. PMid:23562582 https ://doi.org/10.1016/j.womb i. 2013.02 .003

[12] Garnweidner LM, Sverre Pettersen K, Mosdol A. Experiences with nutrition-related information during antenatal care of pregnant women of different ethnic backgrounds residing in the area of Oslo, Norway. Midwifery. 2013; 29(12): e130-7. PMid:23481338 https ://doi.org/10.1016/j.midw.2012.12.006

[13] Othman S, Jayasekara R, Steen M, et al. A systematic review for exploring the effectiveness of healthy eating education programmes for improving midwives' levels of knowledge and confidence in promoting healthy eating in pregnant women. Evidence Based Midwifery. 2018; 16(3): 84-93.

[14] Othman S, Steen M, Fleet JA, et al. Healthy eating in pregnancy, education for midwives: A pre-post intervention study. European Journal of Midwifery. 2020; 4(May). https ://doi .org/10.183 $32 /$ ejm/120004

[15] Adom D, Hussein E, Joe AA. Theoretical and conceptual framework: Mandatory ingredients of a quality research. International Journal of Scientific Research. 2018; 7: 438-41.
[16] Antonenko PD. The instrumental value of conceptual frameworks in educational technology research. Educational Technology Research Development. 2015; 63(1): 53-71. https://doi.org/10.1007/ s11423-014-9363-4

[17] Creswell J. Research design: Qualitative, quantitative and mixed methods approaches. Oaks T, editor. California 2003.

[18] Heale R, Twycross A. Validity and reliability in quantitative studies. 2015; 18(3): 66-7. PMid:25979629 https ://doi.org/10.1136/ eb-2015-102129

[19] Othman S, Steen M, Fleet J, et al. A healthy eating education program for midwives to investigate and explore their knowledge, understanding, and confidence to support pregnant women to eat healthily: Protocol for a mixed-methods study. JMIR Res Protoc. 2018; 7(5): e143. PMid:29802092 https ://doi.org/10.2196/resprot.9861

[20] Noble H, Smith J. Issues of validity and reliability in qualitative research. 2015; 18(2): 34-5. PMid:25653237 https ://doi .org/ 10.1136/eb-2015-102054

[21] Korstjens I, Moser A. Series: Practical guidance to qualitative research. Part 4: Trustworthiness and publishing. European Journal of General Practice. 2018; 24(1): 120-4. PMid:29202616 https : //doi.org/10.1080/13814788.2017.1375092

[22] Hsieh HF, Shannon SE. Three approaches to qualitative content analysis. Qualitative Health Research. 2005; 15(9): 1277-88. PMid:16204405 https ://doi.org/10.1177/10497323052766 87

[23] Othman S, Fleet JA, Steen M, et al. Midwives' views and experiences of providing healthy eating advice to pregnant women: A qualitative content analysis of semi-structured interviews. Frontiers of Nursing. 2020; In Press.

[24] Fielding NG. Triangulation and mixed methods designs:Data integration with new research technologies. 2012; 6(2): 124-36. https : //doi .org/10.1177/1558689812437101

[25] Fetters MD, Curry LA, Creswell JW. Achieving integration in mixed methods designs-principles and practices. Health Serv Res. 2013; 48(6Pt 2): 2134-56. PMid:24279835 https ://doi .org/10.111 1/1475-6773. 12117

[26] O'Cathain A, Murphy E, Nicholl J. Three techniques for integrating data in mixed methods studies. BMJ (Clinical research ed). 2010; 341: c4587. PMid:20851841 https : //doi .org/10.1136/bmj . c4587

[27] Halcomb E, Hickman L. Mixed methods research. Nursing Standard: Promoting excellence in nursing care. 2015; 29(32): 41-7. PMid:25850508 https://doi.org/10.7748/ns.29.32.41.e8 858

[28] Guetterman T, Fetters M, Creswell J. Integrating quantitative and qualitative results in health science mixed methods research through joint displays. The Annals of Family Medicine. 2015; 13: 554-61. PMid:26553895 https : //doi.org/10.1370/afm.1865

[29] Morgan DL. Commentary-After triangulation, what next? 2019; 13(1): 6-11. https://doi .org/10.1177/1558689818780596

[30] Uprichard E, Dawney L. Data diffraction: Challenging data integration in mixed methods research. 2019; 13(1): 19-32. PMid:30595679 https : //doi.org/10.1177/1558689816674650 
[31] Ivankova NV. Implementing quality criteria in designing and conducting a sequential QUAN -QUAL mixed methods study of student engagement with learning applied research methods online. 2014; 8(1): 25-51. https://doi.org/10.1177/1558689813487945

[32] Caracelli VJ, Greene JC. Data analysis strategies for mixed-method evaluation designs. Educational Evaluation and Policy Analysis. 1993; 15(2): 195-207. https://doi.org/10.3102/0162373701 5002195

[33] Fetters MD, Freshwater D. Publishing a methodological mixed methods research article. 2015; 9(3): 203-13. https ://doi .org/10.1 $177 / 1558689815594687$

[34] Arrish J, Yeatman H, Williamson M. Australian midwives and provision of nutrition education during pregnancy: A cross sectional survey of nutrition knowledge, attitudes, and confidence. Women Birth. 2016; 29(5): 455-64. PMid:27020228 https : //doi .org/10 $.1016 / j$. wombi. 2016.03 .001

[35] $\mathrm{Ng}$ Y. The effect of continuing professional development from the perspective of nurses and midwives who participated in continuing education programs offered by Global Health Alliance Western Australia: A mixed-method study University of Notre Dame Australia. 2017. Available from: https://researchonline.nd.edu.au/t heses/155

[36] Katsikitis M, McAllister M, Sharman R, et al. Continuing professional development in nursing in Australia: Current awareness, practice and future directions. Contemporary Nurse. 2013; 45(1): 33-45. PMid:24099224 https://doi.org/10.5172/conu.2013.45.1 .33

[37] Ross K, Barr J, Stevens J. Mandatory continuing professional development requirements: what does this mean for Australian nurses. BMC Nurs. 2013.

[38] Basu A, Kennedy L, Tocque K, et al. Eating for 1, healthy and active for 2; feasibility of delivering novel, compact training for midwives to build knowledge and confidence in giving nutrition, physical activity and weight management advice during pregnancy. BMC Pregnancy Childbirth. 2014; 14: 218. PMid:24996422 https: //doi.org/10.1186/1471-2393-14-218

[39] Lucas C, Charlton K, Brown L, et al. Antenatal shared care: Are pregnant women being adequately informed about iodine and nutritional supplementation? 2014; 54(6): 515-21. PMid:25196454 https://doi.org/10.1111/ajo.12239

[40] Guess K, Malek L, Anderson A, et al. Knowledge and practices regarding iodine supplementation: A national survey of healthcare providers. Women and Birth. 2017; 30(1): e56-e60. PMid:27599944 https://doi.org/10.1016/j. wombi.2016.08.007

[41] Elias S, Green T. Nutrition knowledge and attitudes of New Zealand registered midwives. 2007; 64(4): 290-4. https://doi.org/10.1 $111 / j .1747-0080.2007 .00177 . x$

[42] Arrish J, Yeatman H, Williamson M. Midwives role in providing nutrition advice during pregnancy: Meeting the challenges? A qualitative study. Nursing Research and Practice. 2017; 2017: 11. PMid:28751991 https://doi.org/10.1155/2017/7698510

[43] Soltani H, Duxbury A, Rundle R, et al. Dietary habits and supplementation practices of young women during pregnancy: An online cross-sectional survey of young mothers and health care professionals. BMC Nutrition. 2017; 3(1): 19. PMid:32153801 https://doi.org/10.1186/s40795-017-0137-3

[44] Wennberg AL, Hörnsten $\AA$, Hamberg K. A questioned authority meets well-informed pregnant women - a qualitative study examining how midwives perceive their role in dietary counselling. BMC Pregnancy and Childbirth. 2015; 15(1): 88. PMid:25879462 https://doi.org/10.1186/s12884-015-0523-2
[45] Garnweidner L, Sverre Pettersen K, Mosdøl A. Experiences with nutrition-related information during antenatal care of pregnant women of different ethnic backgrounds residing in the area of Oslo, Norway. Midwifery. 2013; 29(12): e130-e7. PMid:23481338 https://doi.org/10.1016/j.midw.2012.12.006

[46] Lucas C, Charlton K, Yeatman H. Nutrition advice during pregnancy: Do women receive it and can health professionals provide it? Maternal and Child Health Journal. 2014; 18(10): 2465-78 PMid:24748213 https://doi.org/10.1007/s10995-014-148 5-0

[47] Hill AM, Nunnery DL, Ammerman A, et al. Nutrient and food group intakes of low-income pregnant women by race/ethnicity. Journal of Health Disparities Research and Practice. 2018; 12.

[48] Bookari K, Yeatman H, Williamson M. Informing nutrition care in the antenatal period: Pregnant womens experiences and need for support BioMed Research International. 2017; 2017: 16. PMid:28890896 https://doi.org/10.1155/2017/4856527

[49] Malek L, Umberger W, Makrides M, et al. Poor adherence to folic acid and iodine supplement recommendations in preconception and pregnancy: A cross-sectional analysis. 2016; 40(5): 424-9. PMid:27523027 https : //doi .org/10.1111/1753-6405.1255 2

[50] George A, Johnson M, Duff M, et al. Maintaining oral health during pregnancy: Perceptions of midwives in Southwest Sydney. Collegian. 2011; 18(2): 71-9. PMid:21706994 https://doi.org/10.1016/ j.colegn. 2010.10.003

[51] Wagner Y, Heinrich-Weltzien R. Midwives' oral health recommendations for pregnant women, infants and young children: Results of a nationwide survey in Germany. BMC Oral Health. 2016; 16(1): 36. PMid:26988101 https://doi.org/10.1186/s12903-016-019 2-1

[52] Rocha JS, Arima L, Chibinski AC, et al. Barriers and facilitators to dental care during pregnancy: A systematic review and metasynthesis of qualitative studies. Cadernos de Saúde Pública. 2018; 34. https://doi .org/10.1590/0102-311×00130817

[53] American College of Obstetricians and Gynecologists. Oral health care during pregnancy and through the lifespan. In: Obstet Gynecol CON, editor. 2017; 417-22 p.

[54] George A, Lang G, Johnson M, Ridge A, de Silva AM, Ajwani S, et al. The evaluation of an oral health education program for midwives in Australia. Women and Birth. 2016; 29(3): 208-13. PMid:26552339 https://doi.org/10.1016/j. wombi.2015.10.004

[55] Perriman N, Davis DL, Ferguson S. What women value in the midwifery continuity of care model: A systematic review with metasynthesis. Midwifery. 2018; 62: 220-9. PMid:29723790 https: //doi.org/10.1016/j.midw.2018.04.011

[56] Wall CR, Gammon CS, Bandara DK, et al. Dietary patterns in pregnancy in New Zealand-influence of maternal sociodemographic, health and lifestyle factors. Nutrients. 2016; 8(5): 300. PMid:27213438 https://doi.org/10.3390/nu8050300

[57] Kocher EL, Sternberg Lamb JM, McGarvey ST, et al. Conceptions of pregnancy health and motivations for healthful behavior change among women in American Samoa. Women and Birth. 2018; 31(1): e32-e41. PMid:28662836 https://doi .org/10.1016/j . wombi. 2017.06 .011

[58] Bornhauser C, Quack Lotscher K, Seifert B, et al. Diet, medication use and drug intake during pregnancy: Data from the consecutive Swiss Health Surveys of 2007 and 2012. Swiss Medical Weekly. 2017; 147: w14572. https://doi.org/10.4414/smw.2017.1 4572

[59] Walker R, Blumfield M, Truby H. Beliefs and advice-seeking behaviours for fertility and pregnancy: A cross-sectional study of 
a global sample. 2018; 31(4): 486-95. PMid:29659064 https:

//doi.org/10.1111/jhn.12554

[60] Faithfull-Byrne A, Thompson L, Schafer KW, et al. Clinical coaches in nursing and midwifery practice: Facilitating point of care workplace learning and development. Collegian. 2017; 24(4): 403-10. https://doi.org/10.1016/j.colegn.2016.06.001 